\title{
GENETIC VARIATION BETWEEN TWO MICROCTONUS HYPERODAE POPULATIONS IMPORTED FOR CONTROL OF ARGENTINE STEM WEEVIL
}

\author{
L.M. WINDER, S.L. GOLDSON and C. LENNEY WILLIAMS
}

\author{
AgResearch Grasslands, PO Box 60, Lincoln, Canterbury
}

\begin{abstract}
Collection of the parasitoid Microctonus hyperodae from diverse habitats in South America was undertaken to maximise the genetic diversity of parasitoids released in New Zealand. Laboratory studies have shown that the populations varied significantly in such aspects as fecundity, photoperiodic response and morphometrics. The use of tandem repeat primers and PCR to amplify anonymous DNA regions has now enabled differentiation of the populations into two genetically distinct types due to the presence or absence of an as yet unidentified DNA region of approximately $480 \mathrm{bp}$. Using this method, parasitoids can be classified as originating from either the east or west of the Andes. This provides the first molecular evidence of intraspecific genetic variation within $M$. hyperodae.
\end{abstract}

Keywords: biocontrol agent, tandem repeat, PCR, genetic marker, genetic diversity.

\section{INTRODUCTION}

Argentine stem weevil Listronotus bonariensis (Kuschel) (Coleoptera: Curculionidae) is regarded as the most damaging pest of ryegrass in New Zealand (Prestidge et al. 1991). Major damage by the species has also been described during cereal establishment (e.g. Kain and Barker 1966; Watson and Wrenn 1978). In the late 1980s, the thelytokous parasitoid wasp Microctonus hyperodae Loan (Hymenoptera: Braconidae, Euphorinae) was recognised as a potentially useful biocontrol agent against this pest and was imported into New Zealand quarantine from a disparate range of ecoclimatic zones in Brazil, Uruguay, Argentina and Chile (Goldsonet al. 1990). Eight isolated collections of parasitoid were obtained and are referred to here as ecotypes. Following host range testing (Goldson et al. 1994), mass-rearing was undertaken with the subsequent release of half a million parasitised weevils throughout New Zealand, mainly as commercial releases (Goldsonet al 1994; McNeill unpubl. data). Throughout this process, equal numbers of each original ecotype have been released around the country (Goldsonetal. 1994). It is hoped that analysis of patterns of ecotypic establishment will indicate the relative importance of climate-matching and preadaptation in biological control (Goldson et al 1994). It is also hoped to identify which ecotypic characteristics conferred adaptive advantage (Goldson et al. 1994). However, in order to achieve this aim, we must be able to discriminate between ecotypes. Investigations to date have shown some ecotypic variation in $M$. hyperodae fecundity and longevity (Phillips and Baird 1996), development (Barlow et al. 1994) and photoperiodicity (Goldson et al. 1993). However, in order to improve this resolution further, considerable effort has been made using molecular technologies to define genomic differences.

Various methods have been tested including randomly amplified polymorphic DNA (RAPD), restriction fragment length polymorphism (RFLP) analysis of the COI, NDI and A6 regions of the mitochondrial genome, RFLP analysis of the nuclear intergenic transcribed spacer (ITS) region of the ribosomal genes and DNA sequencing of the ITS and COI regions. Each of these approaches failed to differentiate between $M$. hyperodae ecotypes (Lenney Williams unpubl. data). This is in contrast to other intraspecific 
differentiation studies which report much greater variability between lines (e.g. Roerhdanz et al. 1993; Richardset al. 1997) and suggests there is very little genetic variation within this species.

Recently however, some progress has been made using the polymerase chain reaction $(\mathrm{PCR})$ in combination with tandem repeat primers. This contribution reports on developments to date.

\section{Sample collection and storage}

\section{MATERIALS AND METHODS}

Adult $M$. hyperodae from laboratory cultured populations were used in this study. Under culture conditions this species has continued to reproduce parthenogenetically, under obligate thelytoky (Loan and Lloyd 1974). Since its initial importation into quarantine in New Zealand, each M. hyperodae parental line has been maintained independently. $M$. hyperodae from generations 43-48 were used in this study. Six individuals from each of two geographically diverse ecotypes - La Serena (west of the Andes) and Uruguay (east of the Andes), were used to test the methods described.

\section{DNA isolation}

DNA was isolated from individual $M$. hyperodae using Chelex-100 (BioRad). The method was a modification of that discussed by Walsh et al. (1991). Individual specimens were placed in sterile $500 \mu \mathrm{l}$ microtubes and frozen in liquid nitrogen. The sample was then ground with the melted end of a pipette tip. Thereafter $200 \mu \mathrm{l}$ of wellstirred 5\% Chelex-100 was immediately added to each tube followed by $8 \mu$ of Proteinase K $(2.5 \mathrm{mg} / \mathrm{ml})$. Samples were vortexed and then briefly centrifuged. Tubes were then heated in a thermocycler at $56^{\circ} \mathrm{C}$ for 8 hours, then at $101^{\circ} \mathrm{C}$ for 10 minutes. The samples were stored frozen until further analysis.

Samples for PCR analysis were thawed and vortexed for 5 seconds. They were then centrifuged for $2 \mathrm{~min}$ at $13000 \mathrm{x}$ g. One microlitre of the supernatant was used for a 50 $\mu \mathrm{l}$ PCR reaction.

\section{Primer design}

Primers used in this initial study were tandem repeat sequences SR1 [(GAC) $)_{5}$ and SR3 [(GACAC $)_{3}$ ] as described by Freemanet al.(1993). DNA sequencing of one region amplified by this primer pair resulted in the development of a further primer known as LW5 [CATCCTTAATTGTCGGCAA]. This was used in conjunction with SR1 to amplify DNA.

\section{DNA amplification}

Amplification of anonymous DNA regions was undertaken using the primer pairs discussed above in a $50 \mu \mathrm{l}$ reaction with $39.625 \mathrm{ml}_{\mathrm{dd}} \mathrm{H}_{2} \mathrm{O} ; 5 \mu \mathrm{l} 10$ X Expand PCR buffer; 1 $\mu \mathrm{l}$ dNTPs $(10 \mathrm{mM})$ [Boehringer Mannheim]; $1.5 \mu \mathrm{l}$ of each primer $(10 \mathrm{mM}) ; 0.375 \mu \mathrm{l}$ Expand HiFidelity polymerase enzyme (1 U/ $\mu \mathrm{l})$ [Boehringer Mannheim] and $1 \mathrm{ml}$ template DNA. Reactions were overlaid with two drops of mineral oil. The thermal cycler was programmed for 35 cycles of $94 / 48 / 72^{\circ} \mathrm{C}$ for $1 / 1 / 2$ minutes. Amplification products were electrophoresed in agarose ( $2 \%$ SeaKem LE in $0.5 \mathrm{X} \mathrm{TBE})$, stained with ethidium bromide, and viewed by UV transillumination.

\section{RESULTS}

For the first time, repeatable genomic differences have been identified in this study. Polymerase chain reaction amplification using the primer pair SR1/SR2 resulted in the amplification of approximately 20 gene regions as shown in Fig. 1 . Three bands $(\alpha, \beta$ and $\gamma$; Fig. 1A), each approximately 600 bp in size, differed between samples from La Serena and Uruguay. These bands were isolated from the gel by jabbing a pasteur pipette into the agarose gel and adding the gel fragment plus DNA to a further PCR reaction. Reamplification using the SR1/SR2 primer pair resulted in three individual bands that corresponded in size with the original bands (Fig. 1B). Following purification of the PCR product using a Wizard (Promega) procedure, DNA sequence analysis was undertaken by the Centre for Gene Research, University of Otago, New Zealand.

One of the three regions amplified (band $\gamma$; Fig. 1B) appears to be a microsatellite region with the sequence (AAACCCGGG) $)_{n}$. The two other regions (bands $\alpha$ and $\beta$; Fig. 


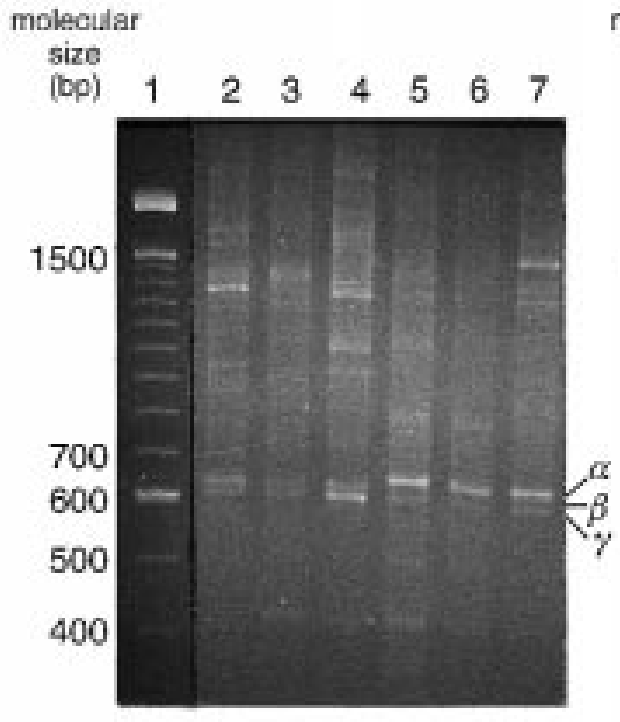

$1 \mathrm{~A}$

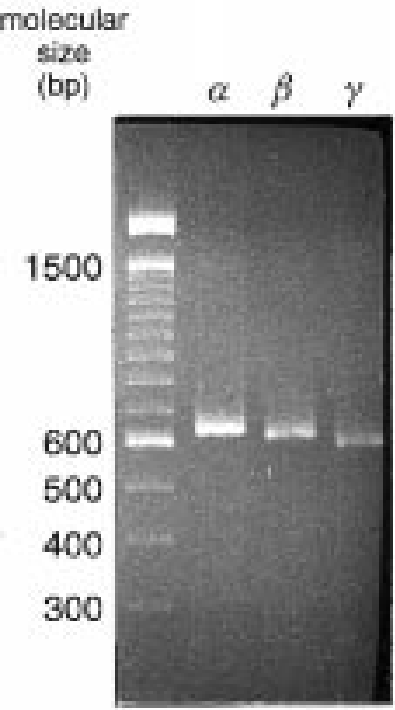

1B

FIGURE 1: (A) PCR amplification banding patterns from individual $M$. hyperodae from La Serena (1A; lanes 2-4) and Uruguay (1A; lanes 5-7). (B) Reamplification of individual bands $\alpha, \beta$, and $\gamma$. All amplifications resulted from use of the primer pair SR1/SR2.

1B) were not repeat regions and as yet have not been identified using currently available databases (BCM Search Launcher, Human Genome Center, Baylor College of Medicine, Houston, Texas).

Specific primers were made to regions within bands $\alpha$ and $\beta$. A study of amplification products with these, and the original SR 1 and SR2 primers, showed that the primer pair SR1/LW5 resulted in amplification of a single band of approximately $480 \mathrm{bp}$ in DNA extracted from $M$. hyperodae from Uruguay, but not La Serena (Fig. 2). Other primer combinations resulted either in no amplification products, or products (bands) with no size differences between the two ecotypes.

\section{DISCUSSION}

This study presents the first molecular evidence of genomic variation between $M$. hyperodae ecotypes. The use of tandem repeat primers resulted in the development of a primer pair which produced amplification products which reliably distinguished between populations of $M$. hyperodae from La Serena and Uruguay. These preliminary results now provide the basis for a more intensive study of other ecotypes based on the development of a larger database using this genetic marker.

Prior to the success of this approach, the authors had made a number of attempts at differentiating between geographical ecotypes of $M$. hyperodae using DNA based techniques. RFLP analysis incorporating the use of 20 restriction enzymes to screen for variation within 3 mitochondrial regions and 1 nuclear region detected no variation between individuals from each of the eight ecotypes (Lenney Williams unpubl. data). RAPD analysis using 40 10-mer primers also identified no consistent variation between ten individuals originating from three ecotypes (Ascasubi, Brazil and La Serena) (Lenney Williams unpubl. data). Additionally, DNA sequencing of the COI and ITS regions also provided no evidence of inter-ecotypic variation (Winder unpubl. data). In contrast to the 


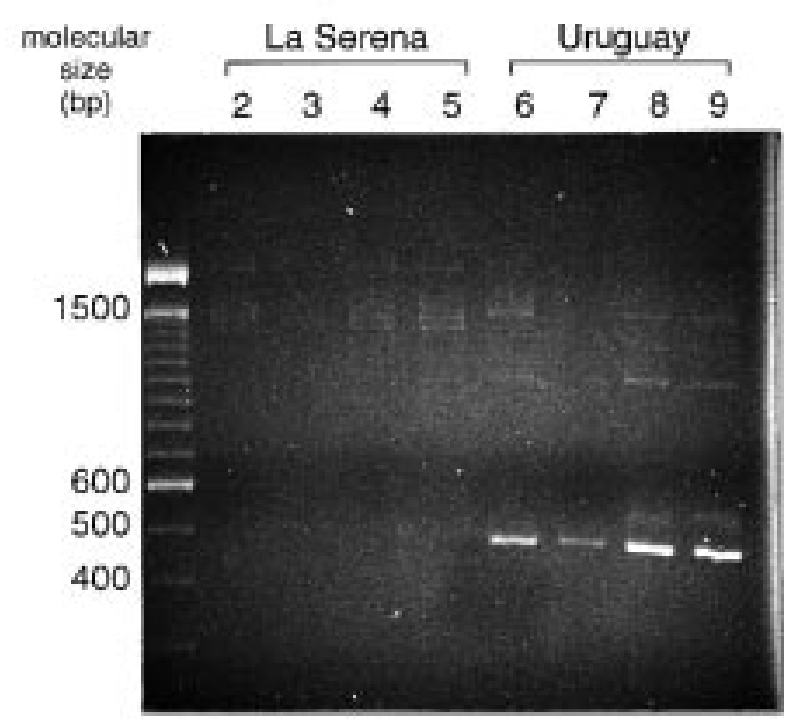

FIGURE 2: PCR amplification banding pattern of individual $M$. hyperodae from La Serena (lanes 2-5) and Uruguay (lanes 6-9) using the primer pair SR1/LW5. This shows the presence of an amplified gene region of approximately 480 bp in Uruguay but not La Serena individuals.

lack of intraspecific differentiation, each of these molecular techniques clearly identified interspecific genetic variation between $M$. hyperodae and $M$. aethiopoides Loan (Lenney Williams unpubl. data.). This therefore, suggested a real lack of genetic variability between $M$. hyperodae individuals.

The genetic variability between the $M$. hyperodae populations from La Serena and Uruguay identified here is further evidence that the South American populations are not genetically uniform in spite of their parthenogenetic reproduction. That this is not a mutation occurring during laboratory culture will be confirmed by evaluating earlier generations of various $M$. hyperodae ecotypes currently held in storage. Moreover, this result suggests that in spite of the complexities associated with rearing individual lines in culture (Goldson et al. 1994) through at least 40 generations, the Uruguay and La Serena lines examined here remained pure. There is no reason to believe that the same does not apply to other lines and ecotypes.

The east-west ecotype differentiation presented in this contribution concurred with the morphometric differentiation of populations described by Phillips and Baird (1996). It is anticipated that the development of molecular markers will offer the opportunity to further differentiate between other populations of $M$. hyperodae. Such a technique, in combination with archived $M$. hyperodae populations collected during parasitoid establishment (M.R. McNeill pers. comm.), will enable analysis of the associated population genetics.

\section{ACKNOWLEDGEMENTS}

This work has depended on the expertise of Mark McNeill in maintaining distinct ecotypic lines during the many generations of parasitoid culture. The authors also appreciate the editorial assistance of John Proffitt. Funding was provided by the NZ Foundation of Research, Science and Technology.

\section{REFERENCES}

Barlow, N.D., Goldson, S.L. and McNeill, M.R., 1994. A prospective model for the 
phenology of Microctonus hyperodae (Hymenoptera: Braconidae), a potential biological control agent of Argentine stem weevil in New Zealand. Biocont. Sci. Tech. 4: 375-386.

Freeman, S., Pham, M. and Rodriguez, R.J., 1993. Molecular genotyping of Colletotrichum species based on arbitrarily primed PCR, A + T-Rich DNA, and nuclear DNA analyses. Exp. Myc. 17: 309-322.

Goldson, S.L., McNeill, M.R. and Proffitt, J.R., 1993. Effect of host condition and photoperiod on the development of Microctonus hyperodae Loan, a parasitoid of the Argentine stem weevil (Listronotus bonariensis (Kuschel)).N.Z. J.Zool. 20: 89-94.

Goldson, S.L., Barker, G.M., Barratt, B.I.P. and Barlow, N.D., 1994. Progress in the biological control of Argentine stem weevil and comment on its potential.Proc. N.Z. Grassl. Assoc. 46: 39-42.

Goldson, S.L., McNeill, M.R., Stufkens, M.W., Proffitt, J.R., Pottinger, R.P. and Farrell, J.A., 1990. Importation and quarantine ofMicroctonus hyperodae, a South American parasitoid of Argentine stem weevil.Proc. 43rd N.Z. Weed and Pest Control Conf.: 334-338.

Kain, W.M. and Barker, M.A., 1966. Argentine stem weevil: a pest of maize.Proc. N.Z. Weed and Pest Control Conf. 19: 180-185.

Loan, C.C. and Lloyd, D.C., 1974. Description and field biology of Microctonus hyperodae Loan, n. sp. (Hymenoptera: Braconidae, Euphorinae) a parasite of Hyperodes bonariensis in South America (Coleoptera: Curculionidae). Entomophaga 19 (1): 7-12.

Phillips, C.B. and Baird D.B., 1996. A morphometric methods to assist in defining the South American origins ofMicroctonus hyperodae Loan(Hymenoptera: Braconidae) established in New Zealand.Biocont. Sci. Tech. 6: 189-205.

Prestidge, R.A., Barker, G.M. and Pottinger, R.P., 1991. The economic cost of Argentine stem weevil in pastures in New Zealand. Proc. N.Z. Weed and Pest Control Conf. 44: 165-170.

Richards, M.K., Glare, T.R. and Hall, D.C.A., 1997. Genetic variation in grass grub, Costelytra zealandica, from several regions.Proc. 50th Plant Prot. Soc. Conf.: (this volume).

Roerhdanz, R.L., Reed, D.K. and Burton, R.L., 1993. Use of polymerase chain reaction and arbitrary primers to distinguish laboratory-raised colonies of parasitic Hymenoptera. Biol. Cont. 3: 199-206.

Walsh, P.S., Metzger, D.A. and Higuchi, R., 1991. Chelex-100 as a medium for simple extraction of DNA for PCR-based typing from forensic material.BioTechniques 10: 506-513.

Watson, R.N. and Wrenn, N.R., 1978. Argentine stem weevil control in maize. Proc. N.Z. Weed and Pest Control Conf. 31: 96-102. 